\title{
INTERAKSI WILAYAH PUSAT PERTUMBUHAN MELALUI PENDEKATAN SKALOGRAM DAN GRAVITASI DI WILAYAH PESISIR DAERAH ISTIMEWA YOGYAKARTA
}

\author{
Yusliana $^{1 *}$, Mutiasari Kurnia Devi \\ 1,2Program Studi Perencanaan Wilayah dan Kota, Institut Teknologi Nasional Yogyakarta \\ *Email Koresponden: yusliana@itny.ac.id
}

Diterima: 05-11-2020, Revisi: 13-12-2020, Disetujui: 20-12-2020

(C)2020 Program Studi Pendidikan Geografi, FISE, Universitas Hamzanwadi

\begin{abstract}
Abstrak Pertumbuhan wilayah di Daerah Istimewa Yogyakarta lebih banyak berpusat pada Kawasan Perkotaan Yogyakarta (KPY). Konsentrasi pertumbuhan wilayah ini menimbulkan ketimpangan dan permasalahan lain terkait daya dukung lingkungan di KPY. Pusat-pusat pertumbuhan di luar pusat pertumbuhan eksisting diperlukan, khususnya untuk mengatasi ketimpangan antar wilayah di DIY. Penelitian ini dilakukan untuk mengidentifikasi kecamatan-kecamatan yang berpotensi untuk menjadi pusat pertumbuhan di wilayah pesisir selatan DIY. Penentuan pusat pertumbuhan potensial dilakukan dengan melakukan kombinasi analisis skalogram, model gravitasi, dan jumlah serta sebaran penduduk. Hasil dari kombinasi analisis tersebut menunjukkan Kecamatan Wates sebagai kecamatan yang berpotensi untuk berkembang sebagai pusat pertumbuhan primer. Sementara Kecamatan Kretek di Kabupaten Bantul berpotensi untuk berkembang sebagai pusat pertumbuhan sekunder. Kecamatan Saptosari di Kabupaten Gunungkidul menjadi kecamatan yang berpotensi untuk ditetapkan sebagai pusat pertumbuhan tersier.
\end{abstract}

Kata kunci: Gravitasi; Ketimpangan; Pusat Pertumbuhan; Skalogram; Wilayah

\begin{abstract}
Regional development in Special Region of Yogyakarta is centered on its urban area, namely Kawasan Perkotaan Yogyakarta (KPY/ Yogyakarta Urban Aglomeration Area). This has created regional disparity and other concerns regarding the environmental sustainability in KPY. The new growth center is therefore needed, especially to solve the problem of regional disparity. This research was conducted to identify the district in the south coast of DIY that has the potentiallity to be developed as the new growth center. For this purpose, this research utilizes scalogram analysis combined with the gravity model and demographic analysis. The result shows that Wates District in Kulonprogo Regency has the potentiallity to be developed as the primary growth center in the south coast of DIY. Furthermore, Kretek District in Bantul Regency has the potentiallity to be developed as the secondary growth center. Meanwhile, Saptosari District in Gunungkidul Regency has the potentiallity to be developed as the tertiary growth center.
\end{abstract}

Keywords: grafity, disparity, growth pole, scalogram, regional

\section{PENDAHULUAN}

Pertumbuhan wilayah di Provinsi Daerah Istimewa Yogyakarta (DIY) yang terpusat pada Kawasan Perkotaan Yogyakarta (KPY) menjadi salah satu faktor penyebab tingginya angka rasio gini pada wilayah provinsi tersebut. Konsentrasi aktivitas ekonomi khususnya di bagian utara KPY telah menciptakan kesenjangan antar wilayah yang tinggi, yang ditandai dengan angka gini rasio sebesar 0,423 dan merupakan angka rasio gini tertinggi dibandingkan provinsi-provinsi lain di Indonesia (Yusliana, 2018). Melihat karakteristik pertumbuhan wilayah yang terjadi di DIY ini mendorong munculnya kebutuhan untuk menciptakan pusat-pusat pertumbuhan baru, sebagai antisipasi terhadap keterbatasan daya tampung dan daya dukung lingkungan di KPY. Pusat-pusat pertumbuhan baru ini diperlukan untuk mencapai dua tujuan utama dari pengembangan wilayah, yakni untuk mendorong pertumbuhan 
wilayah sekaligus keseimbangan wilayah, sehingga pusat-pusat pertumbuhan tersebut dapat menjadi generator pertumbuhan dalam skala yang lebih luas (Apostolache, 2014; Bere et al., 2015; Wong, 2015).

Pusat pertumbuhan merupakan wilayah yang memiliki peran sebagai penggerak ekonomi karena memiliki cakupan dan jangkuan pelayanan yang luas, potensi sumber ekonomi serta memiliki tingkat pertumbuhan ekonomi yang lebih cepat dalam skala lokal maupun regional (Rossi, 2020). Pusat Pertumbuhan juga merupakan kawasan yang memiliki potensi untuk dikembangkan karena memiliki keunggulan sumber daya dan geografis yang mampu menggerakkan pertumbuhan wilayah ekonomi yang berada di sekitarnya (Priyadi \& Atmadji, 2017; Putra, 2016). Pusat-pusat pertumbuhan ini diharapkan memberi efek pengganda (multiplier effect) serta menjadi konsentrasi geografis dari sektorsektor ekonomi yang dapat mendorong perkembangan wilayah di sekitarnya (Pratomo, 2014). Sementara penelitian yang dilakukan oleh (Muazir, 2019) menyebutkan pusat pertumbuhan merupakan wilayahwilayah yang mampu mentransfer hasil pembangunannya terhadap wilayah-wilayah sekitarnya karena sejauh ini kecenderungan interaksi antar wilayah maju dan tertinggal belum optimal. Pusat pertumbuhan juga ditandai dengan meningkatnya aktivitas tutupan lahan yang menunjukkan bahwa terjadi peningkatan aktifitas fisik (Dhali et al., 2019). Semakin tinggi aktifitas fisik maka semakin tinggi tarikan interaksi sebab terjadi pergerakan antara satu dengan yang lainnya (Hariyanto, 2017). Hal ini menunjukkan bahwa ada keterkaitan erat antara pusat pertumbuhan dan interaksi (Iyer \& Thomas, 2020; Shi et al., 2019).

Merespon bahwa pusat pertumbuhan memiliki kaitan yang erat dengan interaksi yang saling terhubung sehingga interaksi merupakan bagian dari jaringan yang terdistribusi melalui skala konektivitas dan ukuran hirarki pelayanan (Mansury \& Shin, 2015). Selain itu interaksi juga dipengaruhi oleh jangkuan pelayanan, interaksi fisik, interaksi sosial dan juga interaksi ekonomi (Kartikakirana, 2019; Ditarani \& Wibisono, 2020). Pemilihan kawasan pesisir selatan DIY sebagai fokus pertumbuhan wilayah ini memerlukan upaya perencanaan dan pengelolaan yang memadai, mengingat pertumbuhan di kawasan pesisir memiliki karakteristik yang berbeda dengan pertumbuhan di luar kawasan pesisir (de Andrés et al., 2018). Isu-isu penting, terutama terkait kondisi fisik, lingkungan, dan kondisi sosial masyarakat pesisir perlu menjadi pertimbangan sehingga pertumbuhan kawasan pesisir dapat berkembang secara berkelanjutan (Jiang et al., 2014). Sehingga keseimbangan antar sumber daya yang terdapat di wilayah pesisir dapat dikelola dengan baik (Rempis et al., 2018; Waluyo, 2014).

Kebutuhan untuk menciptakan pusat-pusat pertumbuhan baru ini direspon oleh pemerintah provinsi DIY, dengan mengarahkan perkembangan wilayah di kawasan pesisir selatan DIY. Hal ini dicanangkan dalam visi DIY 2017-2022 untuk menyongsong "Abad Samudera Hindia". Melalui visi ini, perkembangan wilayah DIY mengarah pada upaya untuk mengembangkan aktivitas-aktivitas sosial dan ekonomi di kawasan pesisir selatan DIY. Untuk mendukung upaya perwujudan pertumbuhan kawasan pesisir selatan DIY yang berkelanjutan dengan mempertimbangkan keunikan karakteristik kawasan pesisir tersebut, diperlukan sebuah kajian untuk mengidentifikasi bagian dari wilayah pesisir yang berpotensi untuk menjadi pusat-pusat pertumbuhan.

Terdapat beberapa penelitian terkait dengan pusat pertumbuhan maupun interaksi wilayah. Penelitian terkait dengan pusat pertumbuhan dibatasi pada aspek sosial dan ekonomi seperti yang dilakukan oleh (Suharyanto et al., 2020) penelitiannya dibatasi pada perkembangan pusat pertumbuhan ekonomi pada perbatasan wilayah Indonesia yang diihat dari sudut padang aspek teknis, sosial dan ekonomi. Hasil penelitian tersebut menunjukkan bahwa potensi basis pengembangan pusat pertumbuhan adalah kegiatan bahari. Selain itu (Vertakova et al., 2015) membatasi penelitiannya pada faktor-faktor yang mempengaruhi terbentuknya kutub-kutub pertumbuhan di Rusia. Hasil dari penelitian tersebut menujukan bahwa kutub pertumbuhan terbentuk karena adanya kegiatan industri atau berciri industri baik kegiatan secara spontan maupun terencana. Selain itu beberapa penelitian terkait dengan interaksi wilayah yang membatasi variabel penelitian pada aspek jarak seperti (Kauffmann, 2016) membatasi penelitian pada interaksi tenaga kerja dalam hal ini karyawan yang memiliki pendidikan tinggi di Jerman. Hasil penelitiannya menunjukkan bahwa interaksi komuter tidak hanya dipengaruhi oleh jarak tapi juga batas negara. Sedangkan penelitian yang dilakukan oleh (Putra et al., 2017) terkait dengan interaksi antar wilayah yang dibatasi pada aspek ekonomi berupa sektor unggulan di Mebidangro. Selain itu 
(Irsyad \& Syahnur, 2018) membatasi penelitiannya pada interaksi spasial ekonomi. Hasil penelitiannya menunjukkan bahwa variabel jarak berpengaruh positif dan signifikan terhadap pertumbuhan ekonomi provinsi asal. Melihat beberapa penelitian tersebut terdapat celah kosong khususnya pada interaksi spasial pusat pertumbuhan khususnya kawasan pesisir. Untuk itu peneliti tertarik mengkaji hal tersebut dengan lokus penelitian kawasan pesisir DIY.

Berdasarkan latar belakang tersebut maka peniliti akan melakukan identifikasi terhadap pusat-pusat pertumbuhan potensial di wilayah pesisir selatan DIY ini dilakukan dengan mempertimbangkan variabel konsentrasi sarana dan prasarana, aglomerasi penduduk, serta kekuatan interaksi dengan pusat pertumbuhan eksisting di KPY. Unit analisis yang dipergunakan adalah kecamatan-kecamatan di wilayah pesisir DIY yang terdiri dari enam kecamatan di wilayah Kabupaten Gunungkidul, empat kecamatan di wilayah Kabupaten Kulonprogo, serta tiga kecamatan di wilayah Kabupaten Bantul. Analisis terhadap ketiga aspek pusat pertumbuhan tersebut menghasilkan kecamatan-kecamatan yang potensial untuk menjadi pusat pertumbuhan primer, sekunder, dan tersier di kawasan pesisir selatan DIY.

\section{METODE PENELITIAN}

Analisis deskriptif kuantitatif dengan basis analisis data sekunder dan primer digunakan dalam penelitian ini. Lokasi penelitian terletak di wilayah pesisir selatan DIY dengan unit analisis wilayah tiga belas kecamatan di wilayah pesisir selatan DIY, yang terdiri dari enam kecamatan di wilayah Kabupaten Gunungkidul, empat kecamatan di wilayah Kabupaten Kulonprogo, dan tiga kecamatan di wilayah Kabupaten Bantul. Setiap kecamatan memiliki karakter fisik yang berbeda-beda. Data yang digunakan berupa data sekunder, jarak antar kecamatan, ketersediaan sarana dan prasarana, khususnya berupa fasilitas kesehatan, pendidikan, ekonomi, peribadatan, perkantoran dan fasilitas pendukung lainnya, serta karakteristik penduduk yang diukur melalui jumlah penduduk dan kepadatan penduduk. Data sekunder diperoleh dari Badan Pusat Stastik dan Badan Perencanaan Pembangunan Daerah (Bappeda) Kabupaten Kulonprogo, Kabupaten Bantul dan Kabupaten Gunungkidul. Selain itu data pendukung seperti Rencana Tata Ruang Wilayah (RTRW) DIY, Rencana Zonasi Wilayah Pesisir dan Pulau-Pulau Kecil (RZWP3K) DIY, Rencana Pembangunan Jangka Panjang (RPJP) DIY dan Rencana Pembangunan Jangka Menengah (RPJM) DIY. Data primer dilakukan dengan observasi lapangan serta wawancara terhadap beberapa instansi terkait. Teknik analisis yang dipergunakan terdiri dari analisis Skalogram Guttman untuk mengukur konsentrasi sarana dan prasarana dan analisis gravitasi untuk mengukur kekuatan interaksi antara kecamatan-kecamatan di kawasan pesisir selatan DIY dengan pusat pertumbuhan eksisting di wilayah Kota Yogyakarta. Hasil dari kedua analisis tersebut dikombinasikan dengan analisis terhadap sebaran penduduk di wilayah pesisir selatan DIY untuk menghasilkan kecamatan-kecamatan dengan potensi tinggi untuk ditetapkan sebagai pusat pertumbuhan di kawasan pesisir selatan DIY.

\section{Analisis Skalogram}

Analisis skalogram digunakan untuk menentukan hirarki di setiap kecamatan. Semakin banyak jumlah fasilitas mengindikasikan bahwa wilayah tersebut memiliki pelayanan yang paling tinggi. Semua jumlah unit fasilitas dikonversi ke dalam Indeks Present Absent dengan menggunakan nilai 1 dan 0 untuk setiap jumlah fasilitas (Muta'ali, 2015). Berapapun jumlah fasilitas diberi nilai 1 dan jika tidak terdapat fasilitas maka diberi nilai 0 dan selanjutnya dijumlahkan kedalam baris dan kolom. Tahapan selanjutnya dalam analisis skalogram meliputi:

1. Menghitung jumlah eror

2. Menentukan jumlah orde dengan menggunakan rumus $1+3,3 \log n$ (n merupakan jumlah kecamatan)

3. Menentukan range dari setiap orde dengan menggunakan rumus sebagai berikut:

\section{$\frac{\text { (nilai terting gi-nilai terendah) }}{\text { jumlah kelas/orde }}$}

4. Menghitung tingkat kesalahan yang disebut dengan Coefficient Of Reduction (COR) dengan rumus

$$
=1-\left(\frac{\text { Jumlah eror }}{\text { Jum Kec } x \text { Jum Fas }}\right) \text { Nilai koefisien dianggap layak apabila mencapai 0,9-1. }
$$

5. Menetapkan jumlah orde. 


\section{Analisis Gravitasi}

Analisis gravitasi digunakan untuk menghitung kekuatan interaksi antar wilayah. Analisis ini digunakan untuk mengukur kekuatan keterkaitan antara pusat kegiatan utama dengan pusat pengembangan wilayah dan menentukan kekuatan tempat kedudukan dari setiap pusat kegiatan ekonomi, produksi dan distribusi dalam sistem jaringan jasa, distribusi dan transportasi, serta menentukan sistem. Semakin besar nilai gravitasi menunjukkan bahwa semakin erat hubungan kedua wilayah tersebut, hal ini menujukkan bahwa daya tarik suatu wilayah memiliki pengaruh terhadap potensi yang dimilikinya (Adisasmita, 2013). Formula rumus gravitasi yang digunakan:

$$
\mathrm{I} 12=\mathrm{G} \frac{M 1 X M 2}{J^{2} 12}
$$

Sumber: Muta'ali, 2015.
Keterangan:
I12 = Potensi daya tarik dan interaksi setiap wilayah
M1 = Massa wilayah 1
M2 = Massa wilayah 2
J12 = Jarak antar wilayah 1 dan wilayah 2
$\mathrm{G}=$ Konstanta jarak yang biasanya diberi nilai 2

\section{TEMUAN DAN PEMBAHASAN}

\section{Karakteristik Demografi Kecamatan di Wilayah Pesisir DIY}

Kawasan pesisir selatan Provinsi Daerah Istimewa Yogyakarta memiliki panjang $\pm 113 \mathrm{Km}$ dari ujung timur di wilayah Kabupaten Gunung Kidul sampai ujung barat di wilayah Kabupaten Kulon Progo yang melalui wilayah Kabupaten Bantul. Berdasarkan data RZWP3K (Rencana Zonasi Wilayah Pesisir Dan Pulau-Pulau Kecil) yang termasuk kedalam wilayah pesisir DIY adalah kecamatankecamatan yang terletak di sepanjang pesisir selatan DIY yang terletak di tiga kabupaten yaitu Kabupaten Gunungkidul, Kabupaten Bantul dan Kabupaten Kulonprogo. Kecamatan di wilayah Kabupaten Gunungkidul yang berada di kawasan pesisir DIY terdiri dari Kecamatan Tanjungsari, Saptosari, Tepus, Purwosari, Panggang, dan Girisubo. Kecamatan di wilayah Kabupaten Bantul yang berada di kawasan pesisir terdiri dari wilayah Kecamatan Kretek, Sanden, dan Srandakan. Sementara di wilayah Kabupaten Kulonprogo, kecamatan yang berada dalam kawasan pesisir DIY adalah wilayah Kecamatan Temon, Panjatan, Wates, dan Galur.

Kondisi demografi di kawasan pesisir DIY ditandai dengan peningkatan jumlah penduduk dalam rentang waktu tahun 2013-20120. Kecamatan yang mengalami peningkatan pertumbuhan paling tinggi adalah Kecamatan Temon, dengan tingkat pertumbuhan penduduk rata-rata sebesar 2,2\%. Wilayah lain dengan tingkat pertumbuhan yang tinggi adalah Kecamatan Wates dan Kecamatan Panjatan. Sedangkan kecamatan yang pertumbuhannya menurun selama lima tahun adalah Kecamatan Tepus, Kecamatan Srandakan, Kecamatan Sanden dan Kecamatan Kretek.

Apabila dilihat dari kondisi persebaran penduduk di kawasan pesisir selatan DIY, Kecamatan Wates menjadi kecamatan dengan tingkat kepadatan penduduk tertinggi, dan cenderung mengalami peningkatan dari tahun 2013 hingga tahun 2020. Kecamatan Temon dan Panjatan juga cenderung mengalami peningkatan kepadatan penduduk dalam rentang waktu 2013-2020. Kecamatan Temon menjadi kecamatan dengan laju perubahan kepadatan penduduk tertinggi di kawasan pesisir selatan DIY dalam rentang waktu 2013-2020, dengan persentase laju perubahan kepadatan penduduk sebesar $11,7 \%$. Sementara meskipun pertumbuhan penduduk di Kecamatan Srandakan, Sanden, dan Kretek mengalami penurunan dalam rentang waktu 2013-2030, kepadatan penduduk di tiga kecamatan tersebut termasuk tinggi apabila dibandingkan dengan kecamatan lain di kawasan pesisir selatan DIY. Sedangkan kecamatan yang kepadatan penduduknya paling kecil adalah Kecamatan Tanjungsari, Kecamatan Saptosari, Kecamatan Tepus, Kecamatan Purwosari, Kecamatan Panggang dan Kecamatan Girisubo. 
Pertumbuhan penduduk di wilayah pesisir DIY cenderung terkonsentrasi di pesisir bagian barat khususnya di pesisir Kabupaten Kulonprogo. Laju perubahan kepadatan penduduk tertinggi di kawasan pesisir selatan DIY juga cenderung terjadi di kecamatan-kecamatan yang terletak di wilayah Kabupaten Kulonprogo, khususnya di wilayah Kecamatan Temon, Wates, dan Panjatan.

Tabel 1. Jumlah dan kepadatan penduduk di Wilayah Pesisir DIY Tahun 2013 dan tahun 2020

\begin{tabular}{|c|c|c|c|c|c|c|c|}
\hline No & Kecamatan & $\begin{array}{c}\text { Luas } \\
\text { wilayah } \\
(\mathrm{km} 2)\end{array}$ & $\begin{array}{c}\text { Jumlah } \\
\text { Penduduk } \\
\text { Tahun } \\
2013 \\
\text { (Jiwa) }\end{array}$ & $\begin{array}{c}\text { Jumlah } \\
\text { Penduduk } \\
\text { Tahun } \\
2020 \\
\text { (Jiwa) }\end{array}$ & $\begin{array}{c}\text { Kepadatan } \\
\text { Penduduk } \\
\text { (Jiwa/Km2) } \\
\text { Tahun } 2013\end{array}$ & $\begin{array}{l}\text { Kepadatan } \\
\text { Penduduk } \\
\text { (Jiwa/Km2) } \\
\text { Tahun } 2020\end{array}$ & $\begin{array}{c}\text { Kepadatan } \\
\text { Penduduk tahun } \\
\text { 2013-2020 (\%) }\end{array}$ \\
\hline 1 & Tanjungsari & 71.63 & 28.770 & 29.469 & 402 & 411 & $2.4 \%$ \\
\hline 2 & Saptosari & 87.83 & 37.811 & 39.591 & 431 & 451 & $4.7 \%$ \\
\hline 3 & Tepus & 104.91 & 36.933 & 36.933 & 352 & 352 & $0.0 \%$ \\
\hline 4 & Purwosari & 71.76 & 20.749 & 21.085 & 289 & 294 & $1.6 \%$ \\
\hline 5 & Panggang & 99.80 & 29.250 & 29.677 & 293 & 297 & $1.5 \%$ \\
\hline 6 & Girisubo & 94.57 & 25.740 & 25.887 & 272 & 274 & $0.6 \%$ \\
\hline 7 & Srandakan & 18.32 & 31.246 & 31.218 & 1706 & 1704 & $-0.1 \%$ \\
\hline 8 & Sanden & 23.16 & 32.487 & 31.972 & 1403 & 1380 & $-1.6 \%$ \\
\hline 9 & Kretek & 26.77 & 30.955 & 30.863 & 1156 & 1153 & $-0.3 \%$ \\
\hline 10 & Temon & 36.30 & 26.358 & 29.446 & 726 & 811 & $11.7 \%$ \\
\hline 11 & Wates & 32.00 & 45.637 & 49.279 & 1426 & 1540 & $8.0 \%$ \\
\hline 12 & Panjatan & 44.59 & 35.983 & 39.098 & 807 & 877 & $8.7 \%$ \\
\hline 13 & Galur & 32.91 & 31.533 & 33.073 & 958 & 1005 & $4.9 \%$ \\
\hline
\end{tabular}

Sumber : Hasil analisis, 2020.

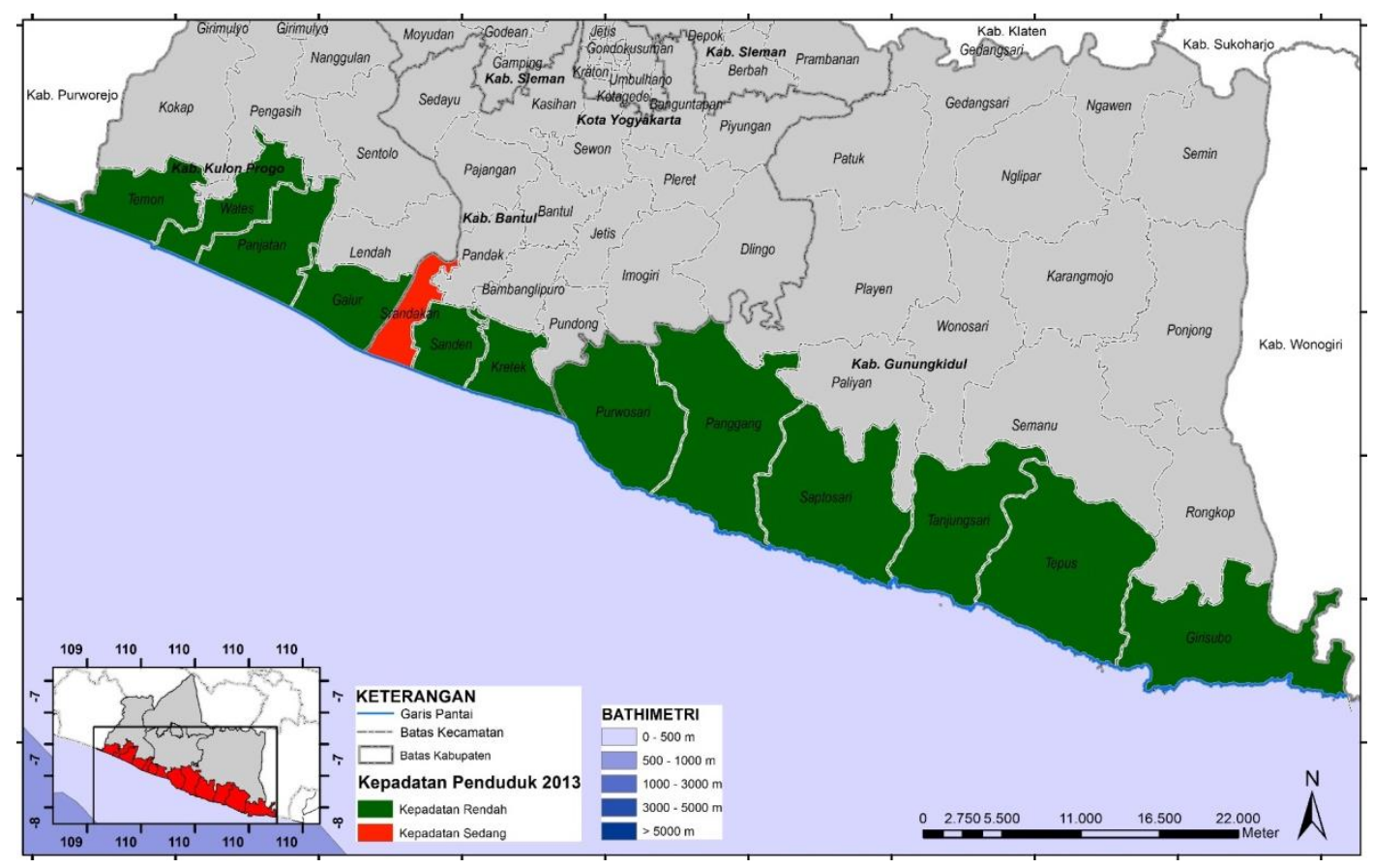

Gambar 1. Peta Kepadatan Penduduk Tahun 2013

(Sumber: Hasil Analisis, 2020) 


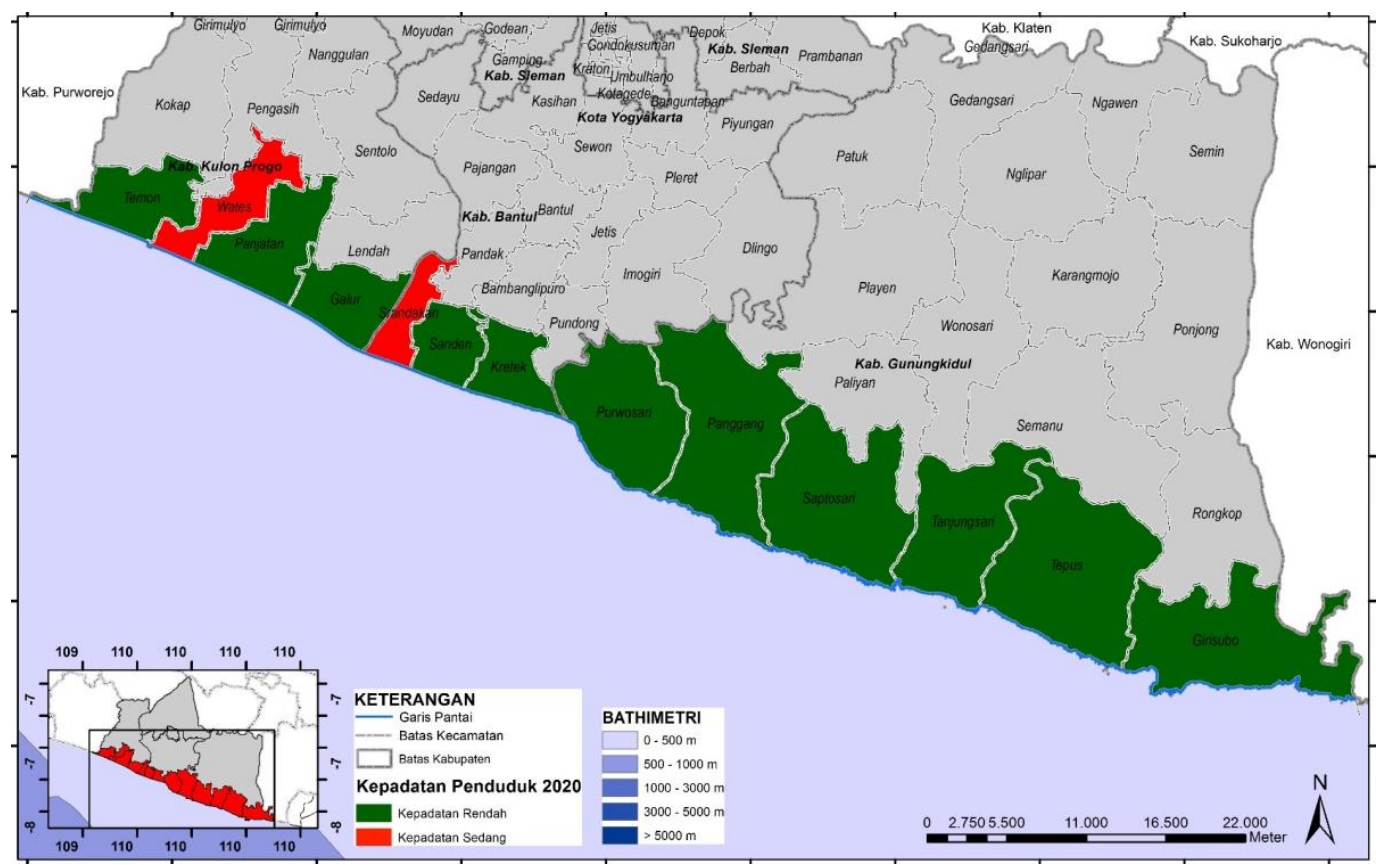

Gambar 2. Peta Kepadatan Penduduk Tahun 2020

(Sumber: Hasil Analisis, 2020)

\section{Analisis Hirarki Wilayah}

Konsentrasi sarana dan prasarana di wilayah pesisir selatan DIY dilakukan menggunakan analisis Skalogram Guttman. Analisis ini menghasilkan orde wilayah berdasarkan ketersediaan sarana dan prasarana yang ada, seperti sarana dan prasarana pendidikan, kesehatan, peribadatan, dan perekonomian. Asumsi yang digunakan adalah wilayah yang memiliki rangking tertinggi adalah lokasi yang ditetapkan sebagai orde tertinggi. Dari hasil analisis skalogram dapat diidentifikasi pusat pertumbuhan kota berdasarkan pada fasilitas-fasilitas perkotaan yang dimiliki disetiap kecamatan.

Data yang dipergunakan di dalam analisis ini adalah data ketersediaan sarana dan prasarana di tiap kecamatan yang berupa jumlah dan titik lokasi data fasilitas perdagangan (pasar), fasilitas peribadatan (mushola, masjid, gereja, dll), fasilitas pendidikan (TK, SD, SMP, SMA dan SMK), fasilitas kesehatan (puskesmas, rumah sakit, dll), dan data fasilitas lainnya. Selanjutnya hasil tersebut dibuat kedalam Index Present Absent dengan menggunakan angka 1 dan 0, dimana angka 1 menunjukkan terdapat fasilitas sedangkan angka 0 menunjukkan tidak terdapat fasilitas. Terdapat 25 jenis fasilitas yang dihitung dengan jumlah fasilitas paling banyak sebanyak 22, paling sedikit sebanyak 15. Dari hasil perhitungan jumlah fasilitas ditemukan jumlah eror sebanyak 22.

Langkah selanjutnya adalah menguji uji kelayakan skalogram dengan menggunakan COR (Coeffietient of Reprodubility). Nilai COR dianggap layak apabila mencapai 0.9 - 1. Hasil uji COR sebesar 0, 93, yang menunjukkan bahwa hasil analisis skalogram valid untuk dipergunakan. Sebelum menetapkan hirarki pusat pertumbuhan maka dilakukan pembagian kelas dengan menggunakan banyaknya kelas yaitu:

$$
\begin{aligned}
& \text { Banyaknya kelas }=1+3,3 \log 13 \\
& =1+3,3(1,139) \\
& =5 \\
& \begin{aligned}
\text { Interval kelas } & =(\text { kelas tertinggi-kelas terendah }) / 5 \\
& =(22-15) / 5 \\
& =1,4
\end{aligned}
\end{aligned}
$$

Hasil pembagian kelas didapatkan 5 orde atau hirarki. Dari hasil analisis skalogram diperoleh bahwa daerah yang dapat ditetapkan sebagai orde 1 adalah Kecamatan Wates dan Kecamatan Kretek jika dilihat bahwa Kecamatan Wates dan Kecamatan Kretek memiliki jumlah dan sebaran fasilitas yang lebih dari kecamatan yang lainnya sehingga kedua wilayah tersebut memiliki fungsi pelayanan bagi wilayah sekitarnya. Hasil analisis menunjukkan bahwa sebaran fasilitas cukup merata, mulai dari fasilitas pendidikan, fasilitas kesehatan, fasilitas peribadatan dan fasilitas perdagangan. 
Hasil analisis skalogram menunjukkan bahwa terdapat beberapa kecamatan yang belum memenuhi kelengkapan sarana kesehatan. Sarana kesehatan hanya terdapat di 3 kecamatan yaitu Rumah Sakit dan Rumah Bersalin yang tersebar di Kecamatan Wates, Kecamatan Temon dan Kecamatan Galur. Padahal fasilitas Rumah Sakit memiliki peranan penting dalam pelayanan kesehatan, sehingga fasilitas tersebut diharapkan mampu untuk dapat melayani dan menjangkau seluruh lapisan masyarakat. Kecamatan yang termasuk ke dalam orde II terletak di Kecamatan Srandakan dan Kecamatan Temon. Secara administratif, Kecamatan Srandakan terletak di Kabupaten Bantul dan Kecamatan Temon terletak di Kabupaten Kulonprogo dan berbatasan langsung dengan Kecamatan Wates. Kecamatan dengan Orde III terletak di Kecamatan Saptosari, Panggang, Sanden dan Galur. Kecamatan dengan Orde IV terletak di Kecamatan Tepus dan Kecamatan Girisubo sementara Kecamatan dengan Orde V terletak di Kecamatan Tanjungsari, Purwosari dan Panjatan.

Tabel 2: Pembagian Hirarki Pesisir DIY

\begin{tabular}{clcc}
\hline No & Kecamatan & Jumlah Fasilitas & Orde/Hirarki \\
\hline 1. & Wates & 32 & I \\
2. & Kretek & 31 & I \\
3. & Srandakan & 30 & II \\
4. & Temon & 30 & II \\
5. & Saptosari & 28 & III \\
6. & Panggang & 28 & III \\
7. & Sanden & 28 & III \\
8. & Galur & 28 & III \\
9. & Tepus & 27 & IV \\
10. & Girisubo & 27 & IV \\
11. & Tanjungsari & 25 & V \\
12. & Purwosari & 25 & V \\
13. & Panjatan & 25 & V \\
\hline
\end{tabular}

Sumber: Hasil analisis peneliti, 2020

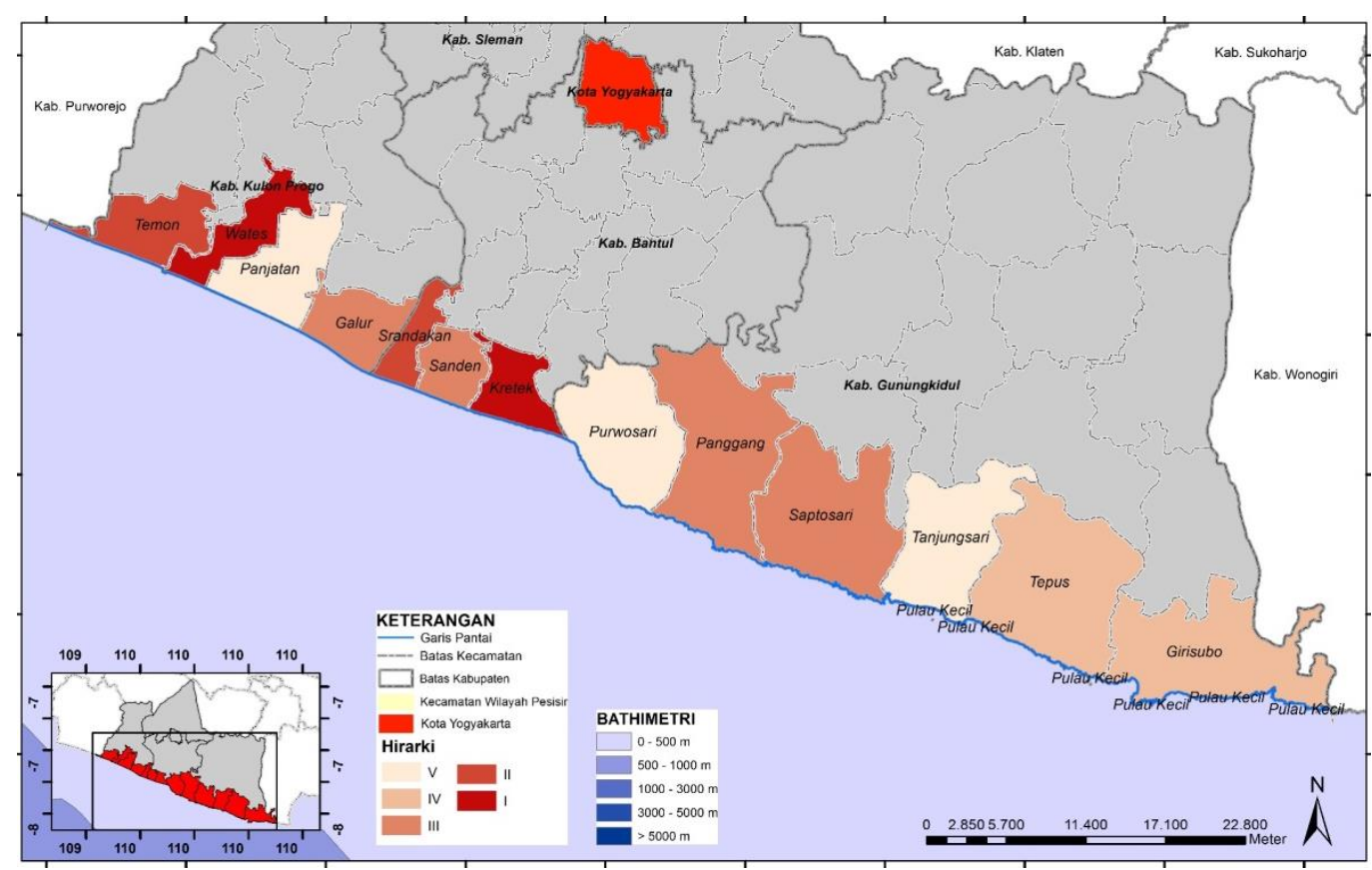

Gambar 3. Peta Hirarki Wilayah Pesisir Daerah Istimewa Yogyakarta (Sumber: Hasil Analisis, 2020)

\section{Analisis Interaksi Wilayah Pesisir DIY}

Salah satu aspek yang perlu dipertimbangkan di dalam merencanakan pusat-pusat pertumbuhan adalah aspek interaksi dengan pusat pertumbuhan eksisting. Interaksi antara kecamatan-kecamatan yang terdapat di kawasan pesisir selatan DIY dengan Kota Yogyakarta sebagai pusat pertumbuhan eksisting 
diukur menggunakan model gravitasi. Model ini mengukur daya tarik menarik antar kota berdasarkan variabel jarak dan jumlah penduduk pada masing-masing wilayah yang berinteraksi (He et al., 2017; Liu et al., 2020).

Dalam model gravitasi yang dilakukan, data yang digunakan adalah data jumlah penduduk di Kota Yogyakarta serta jumlah penduduk di masing-masing kecamatan di kawasan pesisir selatan DIY. Sementara jarak antara masing-masing kecamatan dengan pusat Kota Yogyakarta diukur menggunakan piranti lunak pengolahan data spasial. Jarak yang diukur merupakan jarak lurus terdekat (euclidean distance) dari masing-masing centroid kecamatan dengan centroid Kota Yogyakarta. Hasil pengukuran terhadap jarak ini dinyatakan dalam satuan kilometer $(\mathrm{km})$. Hasil perhitungan gravitasi antara masingmasing kecamatan di kawasan pesisir selatan DIY dengan pusat Kota Yogyakarta dapat dilihat pada tabel 2. Tabel tersebut menunjukkan indeks interaksi antara masing- masing kecamatan di kawasan pesisir selatan DIY dengan pusat Kota Yogyakarta.

Kecamatan Kretek menjadi kecamatan dengan indeks interaksi tertinggi, yakni sebesar 1.00, disusul oleh Kecamatan Sanden dan Kecamatan Srandakan. Ketiga kecamatan tersebut berada di wilayah administratif Kabupaten Bantul. Selain secara geografis jarak antara ketiga kecamatan tersebut dengan Kota Yogyakarta relatif lebih pendek dibandingkan kecamatan lain di kawasan pesisir selatan DIY, ketiga kecamatan tersebut juga telah terkoneksi langsung dengan pusat pertumbuhan eksisting di Kota Yogyakarta melalui keberadaan Jalan Provinsi yang melintasi wilayah ketiga kecamatan tersebut. Di luar ketiga kecamatan di Kabupaten Bantul tersebut, wilayah Kecamatan Wates di Kabupaten Kulonprogo juga memiliki nilai indeks interaksi yang cukup tinggi, yakni sebesar 0,8. Nilai indeks interaksi Kecamatan Wates merupakan yang tertinggi ketiga dibandingkan dengan kecamatankecamatan lain di kawasan pesisir selatan DIY. Interaksi antara Kecamatan Wates dengan pusat pertumbuhan eksisting terdukung oleh keberadaan Jalan Nasional yang merupakan jalan lintas provinsi. Keberadaan Jalan Nasional ini menyebabkan nilai interaksi antara kedua wilayah tersebut tergolong cukup tinggi.

Kecamatan Temon di Kabupaten Kulonprogo memiliki nilai indeks interaksi yang tergolong lemah. Dengan kata lain, dalam kondisi yang ada saat ini, Kecamatan Temon memiliki interaksi yang lemah dengan pusat pertumbuhan eksisting di Kota Yogyakarta. Rendahnya nilai interaksi ini disebabkan oleh faktor jumlah penduduk serta jarak yang cukup jauh dengan Kota Yogyakarta. Perhitungan dalam model gravitasi ini belum memperhitungkan aspek keberadaan Bandara Yogyakarta International Airport (YIA) serta keberadaan moda transportasi yang menghubungkan YIA yang berada di wilayah Kecamatan Temon ini dengan pusat pertumbuhan eksisting di Kota Yogyakarta.

Sementara nilai indeks interaksi antara pusat pertumbuhan eksisting dengan kecamatankecamatan di Kabupaten Gunungkidul cenderung rendah. Selain karena jumlah populasi yang timpang, lemahnya interaksi ini juga disebabkan oleh faktor jarak antara Kota Yogyakarta dengan kecamatankecamatan di wilayah Kabupaten Gunungkidul. Kondisi faktual juga mendukung temuan terkait lemahnya interaksi antara pusat pertumbuhan eksisting dengan kecamatan-kecamatan di Kabupaten Gunungkidul. Tidak terdapat jaringan jalan yang menghubungkan secara langsung wilayah Kota Yogyakarta dengan kecamatan-kecamatan di pesisir selatan Kabupaten Gunungkidul. Selanjutnya posisi masing -masing interaksi spasial antara kecamatan-kecamatan pesisir DIY dengan Kota Yogyakarta dan interaksi antar kecamatan di wilayah pesisir dapat dilihat pada Gambar 4 a dan b.

Tabel 3: Interaksi Wilayah Pesisir dengan Kota Yogayakarta

\begin{tabular}{llcccccc}
\hline No & Kecamatan & $\begin{array}{c}\text { Jumlah } \\
\text { Pendunduk } \\
\text { Wilayah pesisir } \\
\text { DIY }\end{array}$ & $\begin{array}{c}\text { Jumlah } \\
\text { Penduduk } \\
\text { Kota Yogya }\end{array}$ & $\begin{array}{c}\text { Jarak dari } \\
\text { Kota } \\
\text { Yogyakarta } \\
\text { (km) }\end{array}$ & $\begin{array}{c}\text { Nilai } \\
\text { Interaksi }\end{array}$ & $\begin{array}{c}\text { Nilai } \\
\text { Indeks }\end{array}$ & Interpretasi \\
\hline 1. & Tanjungsari & 29.469 & 435.936 & 56.6 & 4010.1 & 0.2 & lemah \\
2. & Saptosari & 39.591 & 435.936 & 45.4 & 8373.51 & 0.4 & sedang \\
3. & Tepus & 36.933 & 435.936 & 61.4 & 4270.71 & 0.2 & lemah \\
4. & Purwosari & 21.085 & 435.936 & 37.3 & 6606.61 & 0.3 & lemah
\end{tabular}




\begin{tabular}{|c|c|c|c|c|c|c|c|}
\hline 5. & Panggang & 29.677 & 435.936 & 32.8 & 12025.3 & 0.6 & sedang \\
\hline 6. & Girisubo & 25.887 & 435.936 & 73.7 & 2077.64 & 0.1 & lemah \\
\hline 7. & Srandakan & 31.218 & 435.936 & 28.4 & 16873 & 0.8 & kuat \\
\hline 8. & Sanden & 31.972 & 435.936 & 26.6 & 19698.3 & 0.9 & kuat \\
\hline 9. & Kretek & 30.863 & 435.936 & 25.3 & 21019.4 & 1.0 & kuat \\
\hline 10. & Temon & 29.446 & 435.936 & 40 & 8022.86 & 0.4 & sedang \\
\hline 11. & Wates & 49.279 & 435.936 & 34.7 & 17841.3 & 0.8 & kuat \\
\hline 12 & Panjatan & 39.098 & 435.936 & 35.5 & 13524.5 & 0.6 & sedang \\
\hline 13. & Galur & 33.073 & 435.936 & 31.5 & 14530.3 & 0.7 & sedang \\
\hline
\end{tabular}

Sumber: Analisis Peneliti, 2020.

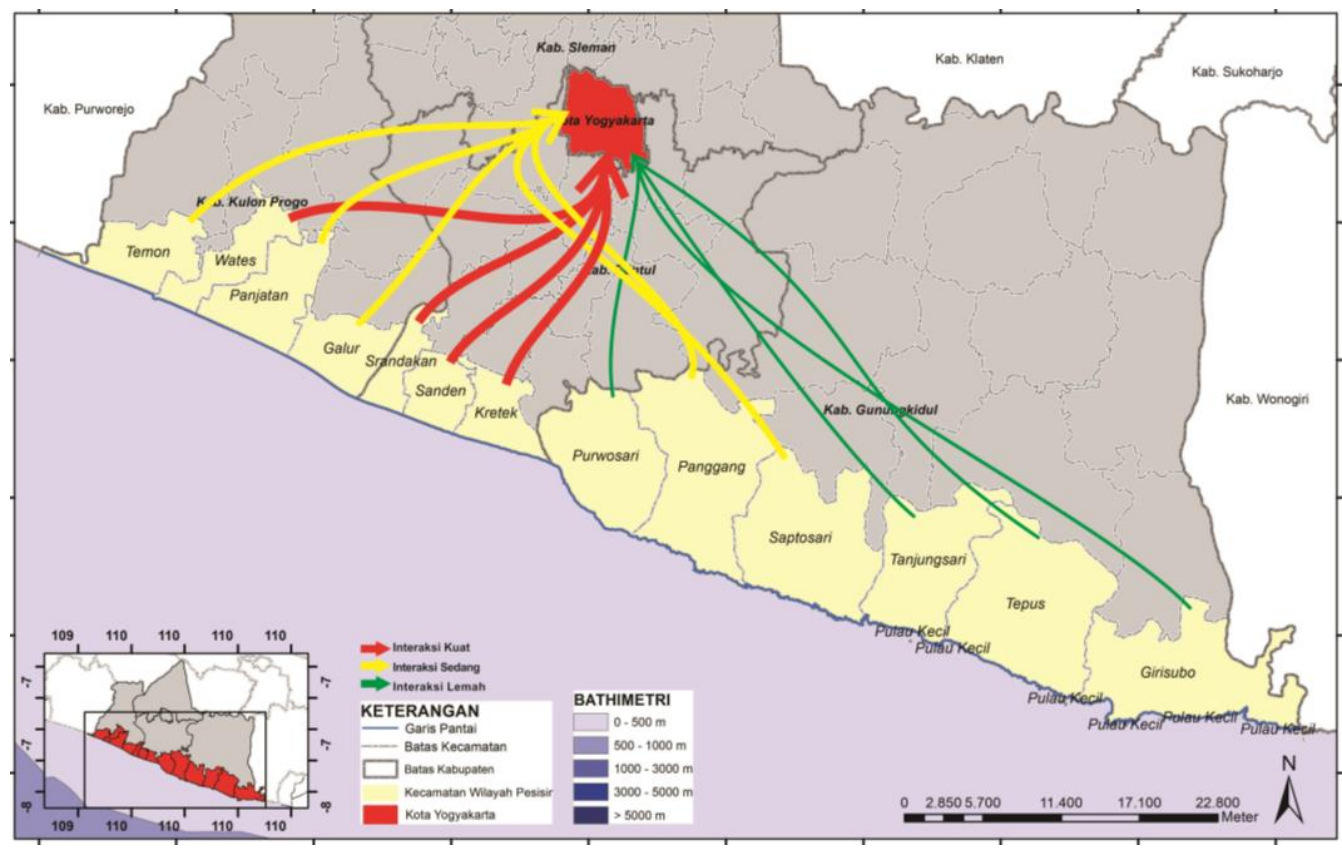

Gambar 4.a. Peta Interaksi Wilayah Pesisir Daerah Istimewa Yogyakarta (Sumber: Hasil Analisis, 2020)

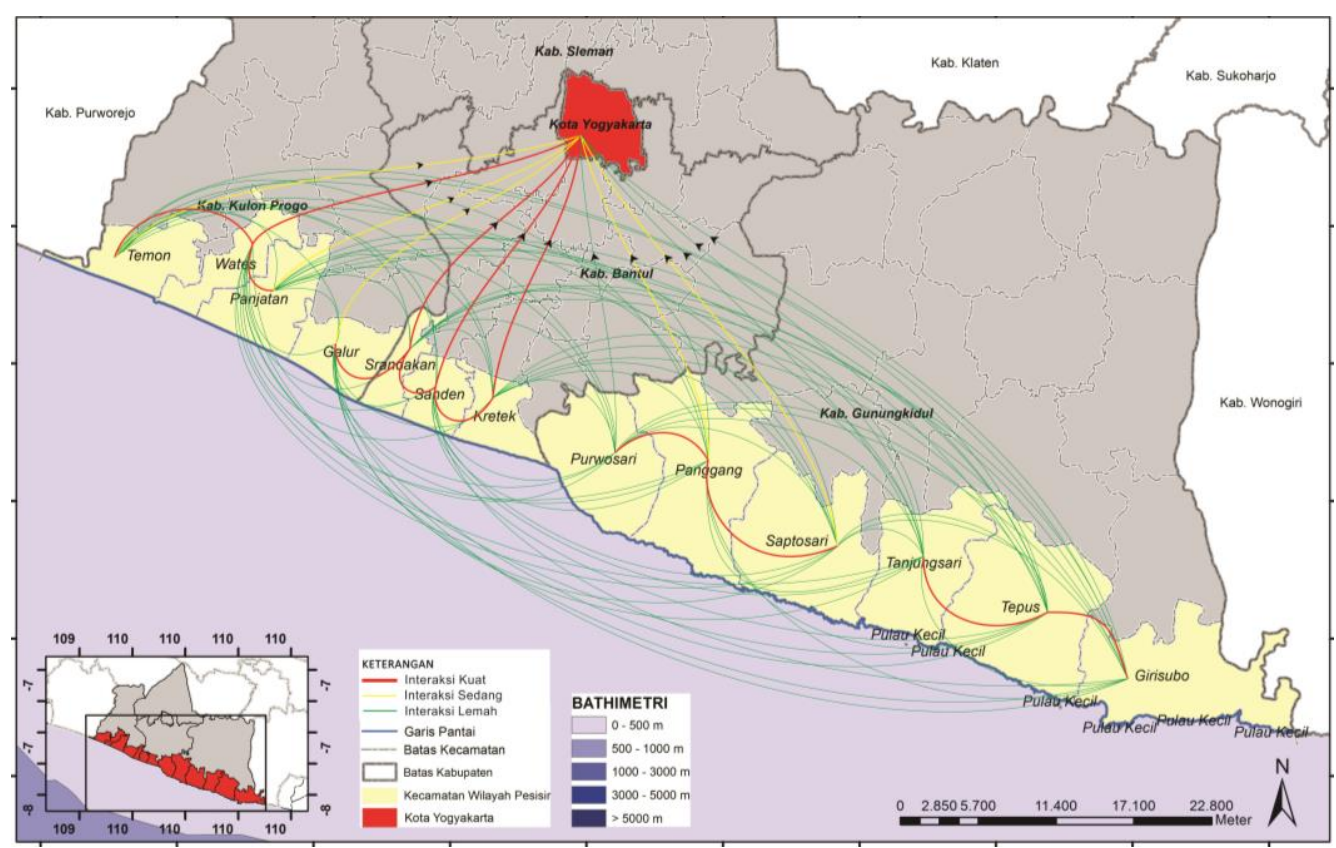

Gambar 4.b. Peta Interaksi Wilayah Pesisir Daerah Istimewa Yogyakarta (Sumber: Hasil Analisis, 2020) 
Berdasarkan hasil analisis yang dilakukan dengan kombinasi antara analisis skalogram dan model gravitasi dengan mempertimbangkan sebaran fasilitas dan kepadatan penduduk maupun jarak antar lokasi diketahui bahwa terdapat tiga kecamatan yang masing-masing memiliki potensi sebagai pusat-pusat pertumbuhan. Kecamatan Wates merupakan kecamatan yang memiliki potensi untuk dikembangkan sebagai Pusat Pertumbuhan Primer yang mampu merangsang pertumbuhan wilayah disekitarnya. Posisi Kecamatan Wates sebagai kecamatan yang berada pada hirarki 1 dan sebagai wilayah Ibukota Kabupaten Kulonprogo yang ditunjang dengan kelengkapan sarana prasarana pada skala kabupaten menjadikan Kecamatan Wates sebagai Pusat Pertumbuhan Primer di wilayah pesisir DIY. Kecamatan Kretek di Kabupaten Bantul berpotensi untuk berkembang sebagai Pusat Pertumbuhan Sekunder. Posisi Kecamatan Kretek yang juga berada pada hirarki 1 dan lokasi berdekatan dengan Kota Yogyakarta dibanding dengan kecamatan-kecamatan lain yang berada di wilayah pesisir menjadikan Kecamatan Kretek memiliki interaksi yang kuat dengan Kota Yogyakarta. Hal ini menunjukkan bahwa terjadi pergerakan yang cukup tinggi diwilayah tersebut. Selanjutnya Kecamatan Saptosari potensial untuk dikembangkan sebagai Pusat Pertumbuhan Tersier yang diharapkan menjadi titik pengaruh yang mampu menjaga kedinamisan wilayah sekitarnya khsusunya wilayah pesisir Kabupaten Gunungkidul. Letak Kecamatan Saptosari yang berada di Kabupaten Gunungkidul manjadikan interaksi di wilayah tersebut sedang yang dipengaruhi oleh faktor sebaran penduduk, sedangkan secara keseluruhan kecamatankecamatan pesisir yang terdapat di Kabupaten Gunungkidul memiliki interaksi lemah yang dipengaruhi oleh jarak dan lokasi.

\section{SIMPULAN}

Dari temuan di atas dapat diketahui bahwa pusat pertumbuhan di wilayah pesisir dibagi menjadi tiga pusat pertumbuhan yang memiliki peran masing-masing yaitu Pusat Pertumbuhan Primer, Pusat Pertumbuhan Sekunder dan Pusat Pertumbuhan Tersier. Dari hasil analisis skalogram diketahui bahwa hirarki 1 berada di Kecamatan Wates dan Kecamatan Kretek dan hasil analisis gravitasi juga menunjukkan kedua kecamatan ini juga memiliki interaksi kuat. Letak Kecamatan Wates sebagai wilayah yang memiliki skala pelayanan tertinggi di Kabupaten Kulonprogo dengan kepadatan penduduk yang tinggi serta lokasi yang strategis sebagai jalur nasional menjadikan Kecamatan Wates sebagai Pusat Pertumbuhan Primer. Selanjutnya Letak Kecamatan Kretek yang berdekatan dengan Kota Yogyakarta menyebabkan terjadi pergerakan penduduk cukup tinggi yang juga berdapampak pada perembetan aktivitas menjadikan Kecamatan Kretek sebagai Pusat Pertumbuhan Sekuder. Sedangkan Pusat Pertumbuhan Tersier ditetapkan di Kecamatan Saptosari untuk melayani wilayah-wilayah yang berada di kawasan pesisir Kabupaten Gunungkidul. Dari hasil penelitian ini diketahui bahwa nilai interaksi dipengaruhi oleh faktor lokasi, jarak dan jumlah penduduk hal ini melengkapi penelitian yang juga dilakukan oleh Kauffman, 2016 bahwa interaksi di pengaruhi oleh jarak dan lokasi. Secara keseluruhan bahwa interaksi wilayah pusat pertumbuhan di wilayah pesisir DIY dipengaruhi oleh kelengkapan sarana prasarana, jumlah penduduk, skala pelayanan serta kekuatan interaksi.

\section{DAFTAR PUSTAKA}

Adisasmita, R. (2013). Ekonomi Tata Ruang Wilayah. Yogyakarta: Graha Ilmu.

Apostolache, M. A. (2014). Regional development in Romania-from regulations to practice. Procedia Economics and Finance, 8(35), 00059-8.

Bere, R. C., Precup, I. B., \& Silvestru, C. I. (2015). On growth poles from EU Countries in the framework of Europe 2020. Procedia economics and finance, 23, 920-925.

de Andrés, M., Barragán, J. M., \& Scherer, M. (2018). Urban centres and coastal zone definition: Which area should we manage?. Land use policy, 71, 121-128.

Dhali, M. K., Chakraborty, M., \& Sahana, M. (2019). Assessing spatio-temporal growth of urban subcentre using Shannon's entropy model and principle component analysis: A case from North 24 
Parganas, lower Ganga River Basin, India. Egyptian Journal of Remote Sensing and Space Science, 22(1), 25-35.

Ditarani, F., \& Wibisono, B. H. (2020). Dampak Peningkatan Kualitas Fisik Terhadap Perkembangan Aktivitas Sosial-Ekonomi di Pedestrian Sudirman Palembang. Geodika: Jurnal Kajian Imu dan Pendidikan Geografi, 4(1), 55-64.

Hariyanto, A. (2017). Studi Pengembangan Ekonomi Lokal Terkait Interaksi Desa-Kota. Jurnal Perencanaan Wilayah Dan Kota, 14(1), 1-14.

He, J., Li, C., Yu, Y., Liu, Y., \& Huang, J. (2017). Measuring urban spatial interaction in Wuhan Urban Agglomeration, Central China: A spatially explicit approach. Sustainable cities and society, 32, 569583.

Irsyad, M., \& Syahnur, S. (2018). Interaksi Spasial Ekonomi di Indonesia. Jurnal Ilmiah Mahasiswa Ekonomi Pembangunan, 3(4), 475-483.

Iyer, K. C., \& Thomas, N. (2020). A Critical Review on Regional Connectivity Scheme of India. Transportation Research Procedia, 48, 47-59.

Jiang, X. Z., Liu, T. Y., \& Su, C. W. (2014). China' s marine economy and regional development. Marine Policy, 50, 227-237.

Kartikakirana, R. A. (2019). Interaksi Spasial di Kota Terpadu Mandiri Lunang Silaut Kabupaten Pesisir Selatan Sumatera Barat. Plano Madani: Jurnal Perencanaan Wilayah dan Kota, 8(1), 36-47.

Kauffmann, A. (2016). Is the 'Central German Metropolitan Region' spatially integrated? An empirical assessment of commuting relations. Urban Studies, 53(9), 1853-1868.

Liu, Y., Zhang, X., Pan, X., Ma, X., \& Tang, M. (2020). The spatial integration and coordinated industrial development of urban agglomerations in the Yangtze River Economic Belt, China. Cities, 104, 102801.

Mansury, Y., \& Shin, J. K. (2015). Size, connectivity, and tipping in spatial networks: Theory and empirics. Computers, environment and urban systems, 54, 428-437.

Muazir, S. (2019). Interaksi Wilayah di Kawasan Strategis Nasional (Perbatasan) dalam Kerangka Jaringan Perkotaan. Jurnal Wilayah dan Lingkungan, 7(1), 1-13.

Muta'ali, L. (2015). Teknik Analisis Regional. Yogyakarta: Badan Penerbit Fakultas Geografi Universitas Gadjah Mada.

Pratomo, A. (2014). Analisis Potensi Pengembangan Pusat Pertumbuhan Ekonomi di Kabupaten Cilacap. Economics Development Analysis Journal, 3(1),13-27.

Priyadi, U., \& Atmadji, E. (2017). Identifikasi Pusat Pertumbuhan dan Wilayah Hinterland di Provinsi Daerah Istimewa Yogyakarta. Asian Journal of Innovation and Entrepreneurship, 2(02), 193-219.

Putra, K. E. (2016). Perencanaan Kawasan Pesisir Sebagai Kawasan Cepat Tumbuh di Kota Medan. Jurnal ArchiGreen, 3(5), 54-60.

Putra, M., Giyarsih, S. R., \& Kurniawan, A. (2017). Sektor Unggulan dan Interaksi Antarwilayah pada Kawasan Strategis Nasional Perkotaan Mebidangro. Jurnal Wilayah dan Lingkungan, 5(3), 181-187.

Rempis, N., Alexandrakis, G., Tsilimigkas, G., \& Kampanis, N. (2018). Coastal use synergies and conflicts evaluation in the framework of spatial, development and sectoral policies. Ocean \& Coastal Management, 166, 40-51.

Rossi, U. (2020). Growth Poles and Growth Centers. International Encyclopedia of Human Geography (Second Edition, Vol. 6). Elsevier. 
Shi, X., Yao, L., \& Jiang, H. (2019). Regional power connectivity in Southeast Asia: the role of regional cooperation. Global Energy Interconnection, 2(5), 444-456.

Suharyanto, S., Zulham, A., Sidqi, M., Sudianto, A., Widianto, A., \& Suraji, S. (2020). Pulau-pulau Kecil Sebagai Pusat Pertumbuhan Ekonomi di Wilayah Perbatasan Indonesia: Review Aspek Teknis, Sosial dan Ekonomi. Buletin Ilmiah Marina Sosial Ekonomi Kelautan dan Perikanan, 6(1), 73-84.

Vertakova, Y., Polozhentseva, Y., \& Klevtsova, M. (2015). The Formation of the Propulsive Industries of Economic Development Acting as the Growth Poles of Regions. Procedia Economics and Finance, 24, 750-759.

Waluyo, A. (2014). Permodelan Pengelolaan Wilayah Pesisir dan Pulau-Pulau Kecil Secara Terpadu yang Berbasis Masyarakat (Studi Kasus di Pulau Raas Kabupaten Sumenep Madura). Jurnal Kelautan: Indonesian Journal of Marine Science and Technology, 7(2), 75-85.

Wong, C. (2015). Regional Planning: China. International Encyclopedia of Social \& Behavioral Sciences (Second Edi, Vol. 20). Elsevier.

Yusliana, Y. (2018). Identifikasi Potensi Ekonomi Wilayah di Kabupaten Bantul. Reka Ruang, 1(1), 2838. 